\title{
INTEGRATING SERVICE LEARNING PROJECTS INTO TECHNOLOGY COURSES: THE EXPERIENCE OF TWO PROGRAMS
}

\author{
Azad Ali Indiana University of Pennsylvania azad.ali@iup.edu \\ Gary J. DeLorenzo, California University of Pennsylvania, delorenzo@cup.edu \\ Scott Mensch Indiana University of Pennsylvania smensch@iup.edu \\ Frederick G. Kohun, Robert Morris University, kohun@rmu.edu
}

\begin{abstract}
This paper details the experience of integrating service learning projects into technology programs within three universities: The Technology Support and Training program (BTST) at Eberly College of Business and Information Technology (ECOBIT) at Indiana University of Pennsylvania (IUP) and the Computer Information Systems (CIS) program within the Math and Computer Science Department at California University of Pennsylvania (CUP). Both departments have implemented policies requiring their students to complete service projects. This study explains the steps that have been undertaken by faculty members at both departments to inquire, select and implement service projects in their technology courses.
\end{abstract}

Keywords: Service learning, technology service projects, computer service projects

\section{INTRODUCTION}

"Service Learning" is a term that is often repeated in academia in reference to projects that involve things like helping the elderly, cleaning streets, teaching disadvantage children, feeding the hungry or similar projects. The emphasis of such projects varies, but the main purpose has most often been to provide learning opportunities for the students while at the same time offer services for organizations or individuals alike. Sheffield [10] explained about the general purpose of service learning:

"Service-learning provides the opportunity to apply classroom-developed knowledge and skills to a community problem thereby increasing the depth and understanding of knowledge and skill while solving a community problem through

\author{
interaction with diverse \\ community stakeholders.”
}

Service projects have been frequently introduced in education, psychology, social science or similar social science courses. The term of "service learning" is repeated often in such course. The same term is not referenced as often in technology courses or when using technology in organizations. In other words, service projects are not introduced in technology courses at the same rate that are introduced in the social science or other related humanities courses.

Despite this limited coverage of service projects in technology courses, some of these courses are able to introduce and incorporate projects that are deemed beneficial to the students as well as to the community.

\section{ABOUT SERVICE LEARNING}

The term service learning is used in education from high schools, community colleges, universities, to a few graduate programs. Despite this wide spread use of service learning projects in academia, there are different terms that describe the definition of such projects, their components, and what goes into adopting them into the classroom.

The use of the term service-learning was coined in 1967 to describe the educational philosophy of integrating classroom concepts with related community service experiences [8]. In a simple definition, Sanderson and Vollmar [9] defined service learning as "the integration of classroom concepts and related community service experience." They further state that "service learning is an educational philosophy that promotes active learning through community service (p 222)”.Ferguson and Liu [3] noted that in service learning projects "students apply the knowledge and skills they have gained in the classroom to the real-world problems of community-based (p. 127)". Other definitions 
described service learning projects more elaborately and discussed the term from different perspectives. The Community Campus Partnership for Health (CCPH) [2] for example connected service learning with preparation and reflection as illustrated in their definition listed below:

"Service-learning is a
structured learning experience
that combines community
service with preparation and
reflection. Students engaged in
service-learning provide
community service in response
to community-identified
concerns and learn about the
context in which service is
provided, the connection
between their service and their
academic coursework, and
their roles as citizens." p. 1.

The National Service-Learning Clearing House [4] defined service learning as a "teaching and learning strategy that integrates meaningful community service with instruction and reflection to enrich the learning experience, teach civic responsibility, and strengthen communities.” The National Youth Leadership Council [5] went a step further in defining service learning. It described service learning as a philosophy and pedagogy and illustrated examples of service learning projects:

"Picking up trash on a riverbank is service. Studying water samples under a microscope is learning. When science students collect and analyze water samples, document their results, and present findings to a local pollution control agency ... that is service-learning. Servicelearning is a philosophy, pedagogy, and model for community development that is used as an instrumental strategy to meet learning goals and/or content standards”.

Chayton [1] defined service learning as "a form of experiential education in which students engage in activities that address human and community need together with structured opportunities intentionally designed to promote students with learning and development. Reflection and reciprocity are key concepts to service learning” P. 226.

Based on the definitions and descriptions listed above, the following components and criteria have been present in service learning projects:

1- A project that deems to provide service assigned to students to work on.

2- An educational course or program that assigns the service project to the students.

3- The beneficiary of the service is a community based organization or individuals.

4- The main goal of the service project is on student learning first and then on providing the service second

\section{Service Learning in Technology Courses:}

Despite the increasing use of service learning projects in academia; the same increase is not witnessed in computer technology related programs. Numerous examples can be cited to indicate that computer technology programs lag behind other disciplines in introducing service projects into their courses. The Community Campus Partnership for Health lists resources and syllabi for a number of different disciplines. However, this list does not include any discipline related to computer science, information systems, information technology or any other similar fields of study. By the same token, the National Service Learning Clearinghouse web site that lists resources for computer science curricula had only three listings present [8]. Sanderson [8] directly indicated the lack of visibility for computer science courses in terms of service learning projects:

"Service-learning is a form of experiential learning that integrates classroom concepts with related community services. Computer science faculty and students stand to reap great benefit from the integration of service-learning practice and philosophy into curricula. Many faculty are already doing so, yet computer science is not very visible in the service-learning community. Similarly, service- 
learning is not very visible in the computer science education community” (p. 83).

The point that can be derived from the statement above is that computer technology related programs are slower than other programs in adopting service learning project into their courses. But this slow adoption may not all be related to the programs themselves. A number of factors may contribute to this slow adoption. Some of these factors are due to the nature of computer related programs while other factors are linked to the general perception of what constitutes a service and the underlying philosophies that underpin service projects and their practices.

Rosmaita [7] noted that when introducing service projects into the classrooms several obstacles will need to be overcome:

- $\quad$ The experience obstacle: students must have experience to provide service.

- The danger obstacle: Some of the applications that are developed may pose a risk. An example would be to design a site that involves colleting donations online and the risks that such collection will be hijacked by computer by hackers.

- $\quad$ The maintenance problem: Sometimes a project may take more than one semester to complete and it may go from one hand to another.

In regards the philosophies that explain service projects, Ward and Wendall [12] differentiated between "doing for" and "doing with" as a general purpose for assigning service learning projects at colleges and universities:

Many colleges and universities seek to enliven their service missions through service learning....... higher education institutions traditionally operate under an orientation of doing for communities rather than doing with them. Doing for is typically aligned with a charity perspective and emphasizes the position of privilege of campuses in relationship to their local communities, whereas a doing with perspective of service emphasizes collaboration and mutuality. Using special focus colleges and universities as a model, the authors provide suggestions on how to shift the paradigm to one that is more community centered.

The charity type of services is more common and is a direct type of service. Examples include feeding the hungry, collecting donations, and helping the elderly. Most computer related programs do not provide this type of direct service and thus any service they provide is deemed to only indirectly provide a service. An example would be the design of a web site for a non-profit organization. Although it is considered a service it does not provide the direct service for the people who need it and may not be looked upon the same way as other service projects.

Despite these difficulties and problems associated with introducing service learning projects into computing curriculums, other opportunities appear from this field. As might be expected, a number of computer programs are jumping on the band wagon and integrating service projects into their computer courses.

Purewal, Bennett and Maier [6] noted that as computers became increasingly used in organizations and as different parts of the society became more dependent on this technology, those working with computers moved into an ideal position to be of use to society. As a result, they proposed a course on computing, ethics and society to be introduced at the beginning of a technology program. Chaytor [1] developed a computer program with the objective of integrating service learning into his college curriculum. It was first offered and introduced to a web publishing class and required the students to create web sites for local small businesses in the community.

As a result a number of computer technology related programs initiated service learning projects. One program started the computer recycling initiative where students in computer programs assemble computers from old parts and donate them to non-profit organizations (Purewa et al P. 556). They also suggested introducing service learning through a course on computing on ethics and society. Sanderson [8] suggested 
the following opportunities for introducing service projects into computer courses:

- Develop an information system for an organization's administrator.

- Develop a web site for an organization or school.

- Develop classroom software for a school.

- Network an organization's computer resources.

- Tutoring and other instructional activities.

\section{Service Learning Projects - Potential Benefits}

Ward and Wendell [12] explained that service learning projects potentially provide benefits for students, for faculty, and for administrators. They further explained that the benefits from the student side included involvement in service influences, career preparation, awareness of community problems, and the connection of theory to practice. One benefit of service projects for faculty is that it is a way to apply theory and knowledge to local problems. For administrators, service is a way to improve relations between campus and community. Sanderson and Volmar [9] elaborated further on the benefits of service learning for students:

Service learning experiences benefit students in many ways besides the experimental learning. The experiences are great resume builder, having many of the benefits of internship with smaller time commitments. Successful service learning experiences build self confidence and allow students to test drive their career choices before graduation. They also provide valuable experiences in citizenship, by exposing students to larger societal issues they may have previously avoided or seen only as abstractions. (p. 222).

Ferguson and Liu [3] noted that incorporating service learning projects into the curriculum has positive benefits for attracting and retaining female students. They noted further that "working with non-profit organizations strengthens women's commitment to using computers to help others” (p. 127). Chaytor [1] noted that through service learning projects students can improve interpersonal skills and awareness of civic engagement.

In a study that is conducted to assess the efficacy of introducing service-learning pedagogy to promote mutual partnership between academic institutions and their respective communicates. The study found that there is a barrier in what it termed as "digital citizenship". It referenced this term when it found that a special group of vulnerable people are unable to take advantage of the Internet the same way that people with higher level income do. Thus according to the study there is a "digital divide" between the people who are well enough to access the Internet on their own and between the people who are most vulnerable and unable to access the Internet. The study reported about the experience of two universities who integrated service learning projects where student educate vulnerable people about the use of the Internet. The same study concluded that the work of the students who participated in these projects contributed to reducing to what it called it the "digital divide" that surrounds the use of the Internet.

The conclusion that can be drawn from the above is that service learning project helps in more way than one. The extent at which these service projects help is still subject various opinions. The remainder of this section elaborates further and delves into more details about the potential benefits that can be gained from introducing service learning projects into computer related courses.

Practical Experience:

Service learning opportunities provide a student with practical hands on experience in their field of study [1]. This real life experience prepares the students for the real world while instilling the important concept of community service. The opportunity to transfer both theory and hands on learning in a controlled environment to the practical world must not be underestimated.

As with higher education, junior and senior highschool students are increasingly partaking in service learning to both prepare students as well as to install the importance of community service. It has also been suggested that service projects will reduce crime and protect students 
who are the victims of crime. Donovan notes that "the Teens, Crime, and Community (TCC) program, a nationally recognized crime prevention and service learning program, has combined community service with crimeprevention education to reduce high teen victimization rates.”

Regarding the specifics of computer technology, Purewal, Bennett and Maier [6] suggest that service learning addresses three negative influences on computer majors: first, aversion to sitting in front of a computer all day; second, the fact they already have chosen a major; and third, that they would be more interested in peopleoriented majors or occupations (P. 556).

\section{Service Learning Projects - Making it Work}

While introducing service projects into academic programs are deemed helpful to both the community and to the university, introducing such courses are not always straight forward processes. This experience of service learning is dissimilar to other courses, thus it may have some requirements that need to be addressed separately in order to make it work. The National Youth Leadership Council for example lists six factors that contribute to make service projects work: Youth ownership or ownership of service projects by students, genuine community needs, connection to learning objectives, reflection, partnerships, and making it happen. Chaytor [1] noted that to make service learning effective, there must be integration into college curriculum and sustainability.

\section{Facilitating with the Community}

In order for a service learning project to be added to a college curriculum there must be a need by the community. The recipients of the service in these projects are likely to be an organization(s) or charities. In order to make sure that the service project works effectively, there is a need to facilitate at more than one level with the organization and work on some of the logistics to coordinate resources and scheduling. A number of problems can occur in service projects [6] such as:

- The students go to a meeting and the organization representatives do not show up.

- University students are often busy during the day which is a good time for the organizations to meet which creates scheduling conflicts.

- Often service projects are suggested to meet on Saturday mornings which frustrated the students

In regards to computer technology, this is complicated further as software and hardware compatibility issues may exist between the organizations and the university. Sometimes a student may be trained on a particular program only to find that the organization may be using a different program or platform. Thus a study of these compatibility issues may need to be addressed before launching such service projects.

\section{Integrating Service Projects into the Curriculum}

When adding a particular service project into an existing curriculum or program, a number of potential issues must be addressed. These issues may encompass the students, the department, and the college in general. Service projects may require the involvement of more than one faculty and department, thus it is important to have institutional support for these service projects. Sanderson and Vollmar [9] note the importance of institutional and departmental support for service learning projects in order to make them work because of the impact that such project have on the student, the department and the institution.

Coordinating with students schedules is important because some of these service projects may take trips outside of the college/university and may required them to miss other classes. Some of the projects may take more than one semester to complete leading to questions of the continuity of these projects. If a project continues beyond the timeline of one semester/quarter, it may be a good idea to institutionalize procedures for handing the projects from one class to another and from one faculty to another. Another issue that needs to be addressed is the time gives to the students to reflect on their work. Reflection is an important component in the full realization of benefits of the project

\section{Evaluating Service Learning Projects}

As noted earlier, the main purpose of service projects is on learning first. Thus, it is important to evaluate the learning of the students. A 
common principle in evaluating student performance in is to evaluate all students equally. Exams are ideal for evaluating the performance of students equally. The same questions are asked of all the students, thus measuring the performance of the examinee is going to follow one set of criteria. The same thing may not be applied to service projects. The success of service projects depends on multiple levels of parameters including communication, adherence to time, analyzing what the project is asking them to do and other factors. Added to all of that, service projects may require time commitments that may not be standardized across the projects, thus evaluating the students based on the time spent will be difficult.

Technology projects introduce a number of other elements that may come into play. The software and hardware compatibility between the organization and what the students learned may become a factor in determining the completion of the project. The level of the difficulty of the project may different from one project to another depending on the software/hardware and personal. All these factors need to be addressed prior to getting the students involved in the service learning project.

\section{The TST Program at IUP}

The Technology Support and Training (TST) department in Eberly College of Business and Information Technology (ECOBIT) at Indiana University of Pennsylvania (IUP) offers a bachelor degree in business technology support. The main coverage of this degree is on end user support, networking, and web design and development.

Although service learning projects have been implemented in the TST department, they have been limited mainly to student clubs. The department has a number of clubs (organizations) for their students and each club has a faculty advisor. The faculty advisor works with the students to implement particular service projects. Students form different clubs and they work individually or collectively to provide services to different organizations or individuals in the community.

However this experience of providing services has recently changed with faculty in the TST department now integrating service projects into their courses. Faculty teaching two particular courses have taken active steps to incorporate service projects into their courses. These two courses are BTST402 - Web Site Development and Administration and BTST413 Enterprise Technology Support.

The BTST402 course teaches web development for students enrolled in the technology program at IUP. The primary emphasis of the course is on the server side of the web design. However, the course covers other topics such as client-side web, Internet security and other related topics. In addition BTST413 provides a comprehensive and practical knowledge of enterprise wide technology. Topics covered include knowledge management, remote user support, teleconferencing, and network management and enhancement. Students will have hands-on experience working with software, customizing user environments, managing technology security, and enhancing and troubleshooting the computing environment.

Starting from the spring 2008 semester, the faculty teaching BTST402 embarked on an initiative to provide a service project for designing web sites for local agencies in the surrounding community. Specifically, the course intended to provide expertise in designing web pages for non-profit organizations. To facilitate this work, the faculty communicated with the career service office at the university in order to approach non-profit organizations. An email was sent to 40 local agencies promoting the web service project to solicit interest. The email explained about the interest of the faculty, the benefits that it potentially bring to the agency as well as to the value added to the students. It also suggested meeting with them to further discuss this payment. Eight agencies responded and attended a meeting at the beginning of the semester in January 2008.

During the meeting, the faculty and the representative from various organizations met and took notes about the discussion in general. In cases, some of the projects were discussed at length and additional steps were recommended for follow up. In the end, the faculty added this requirement to the course that the students have to work in groups to complete service projects related to designing/updating web sites for local agencies. Additional steps are currently being taken to explain the details of this requirement and to invite the agencies once again to explain to the students about their intended project. This project is still in progress and measures are taken to ensure successful implementation from the 
agencies' side as well as from the faculty and the department side.

In regards to the second course that was mentioned above, the students in the BTST413 course have solicited used computers and peripherals from both faculty and the student body. These donated machines are then refurbished and donated to nonprofit institutions within the community such as Big Brothers and Big Sisters, community centers, and women's shelters.

\section{The CIS Program at CUP}

The CIS program at California University of PA had taken a different approach to introduce service learning. This approach is detailed as a demonstration of a few individuals - a corporate contact and a faculty member initiated the successful learning services program. The story is as follows. In the summer 2005, the president of Gateway Resources, an IT consulting firm in Pittsburgh, Pennsylvania and an assistant professor at California University of Pennsylvania, met with the Director of Volunteers and the Chief Archivists at the HHC to determine "how can volunteers help out in building and supporting information systems for center?" Initial analysis of the information technology (IT) organization revealed an IT staff primarily involved in help desk services and network administration. With a staff of two fulltime employees, no one provided the role of application systems development. The maintenance of the HHC's web site was outsourced, for both operations and content management. The L\&A function used the MS Office tools extensively, but without having centralized and uniform versions of data, they found themselves with multiple versions of spreadsheets and databases which made it difficult for consistent report generation. The overall solution was the creation between the Heinz History Center and the Math and Computer Science Department of a "volunteer applications development" group with students and faculty from California University of PA to meet the systems development needs of the HHC.

An initial activity included an "application inventory assessment" to determine potential information system projects that needed attention and the fit for the volunteer applications development group based. Project proposals were evaluated against particular courses and student skill sets to determine the technical, business, and communications skills required for students to do the work. From this analysis, an overall "IT Project Plan and Schedule" was defined to manage and drive the workload demands while identifying the specific projects to develop. During the spring 2007semester, the first two applications projects were brought into the classroom. The two projects were:

- As part of course CSC150, Introduction to Database Applications, two students designed a normalized entity relationship diagram (ERD) for a centralized database to track and manage L\&A archival accessions such as books, maps, photographs and clothing. From the ERD, data was imported into a MS Access database for over 8,000 accessions on attributes such as accession type, donor, location, size and category.

- As part of the capstone courses CSC490 and CSC492, Senior Project I and Senior Project II, three students designed and developed a web-based volunteer application to market and recruit new volunteers to the HHC.

To keep the collaboration momentum moving, additional service learning projects were kicked off in the fall 2007 through the spring 2008 semesters. One in particular that gained notoriety was the development and implementation of a client/server application system to track the Westinghouse Electric Corporation's 1,000 films donated to the Library and Archives function. This project, which was also well received, was the key deliverable and capstone project for three students graduating in the Computer Information Systems Program for the spring 2008 term.

\section{SUMMARY AND FUTURE PLAN}

This paper explained the components of service learning projects and how they are planned to be integrated into technology courses. It focused on the experiences of faculty at the BTST department at IUP and the CIS department at CUP. It explained about the steps that have been 
taken to introduce such projects into courses within both programs.

While these projects are still in the beginning phases, there is a need to continue and widen this experience of introducing service projects into technology courses. The intention of the authors of this paper is to follow this study by conducting a follow up survey of the students and the organizations that the services were introduced for. Such a survey may give perspectives on future steps that may need to be undertaken to expand on the current service projects. So the current plan is to continue on the same service projects that they worked on and widen the scope for each project to be more inclusive based on the lessons learned from this current project. Once additional projects will be completed, the authors of this paper see a need for another study to asses the experience of service learning projects in these two programs as a whole.

\section{REFERENCES}

1. Chaytor, L. (2003). Urban Empowerment: A Successful Example of Service Learning. CITC4, 03, October 16-18. Retrieved December 20, 2007 from ACM Digital Library http://www.acm.org/dl

2. Community Campus Partnership for Health (2008). Service-Learning. Retrieved March 15, 2008 from http://depts.washington.edu/ccph/servicelear ningres.html.

3. Ferguson, R. \& Liu, C. (2006). ServiceLearning Projects: Opportunities and Challenges. SIGSCE, March 1-5, 2006 Retrieved December 20, 2007 from ACM Digital Library http://www.acm.org/dl

4. National Service Learning Clearninghouse (2008). Service Learning. Retrieved March 23, 2008 from http://www.servicelearning.org .

5. National Youth Leadership Council (2008). What is Service Learning? Retrieved March 15, 2008 from http://www.nylc.org/discover.cfm?oid=3152

6. Purewal, T.; Bennett, C. \& Maier, F. (2007). Emracing the Social Relevance: Computing, Ethics and the Community. SIGCSE 07, March 7-10, 2007. Retrieved December 20, 2007 from ACM Digital Library http://www.acm.org/dl

7. Rosmaita, B. (2007). Making Service Learning Accessible to Computer
Scienctists. SIGCSE 07, March 7-10, 2007. Retrieved December 20, 2007 from ACM Digital Library http://www.acm.org/dl

8. Sanderson, P. (2003). Where's (The) Computer Science in Service Learning? Consortium for Computing Sciences in Colleges, retrieved February 10, 2008 from ACM digital Library http://www.acm.org/dl.

9. Sanderson, P. \& Vollmar, K. (2000). A Primer for Applying Service Learning to Computer Science. Retrieved February 11, 2008 from ACM Digital Library http://www.acm.org/dl.

10. Sheffield, E. (2005). Service in ServiceLearning Education: the Need for Philosophical Understanding. High School Journal, Vol. 89 Issue 1, p46-53, 8p

11. Shulman, S. \& Beisser, S. \& Larson, T. \& Shelley, M. (2008). Digital Citizens: Lessons Learned as Service-Learning Meets the Digital Divide. Retrieved February 21, 2008

from http://www.drake.edu/artsci/faculty/sshulma n/ITR/.

12. Ward, K. \& Wolf-Wendell, L. (2000). Community Centered Service Learning. American Behavioral Scientist, Vol. 43, No. 5, 767-780. Retrieved March 15, 2008 from http://abs.sagepub.com/cgi/content/abstract/ 43/5/767. 